\title{
Mitteilungen
}

\section{In memoriam Karl Oettle}

Es fällt schwer, diese Zeilen zu schreiben. Seit 4. November 2009 trauern seine Familie und Freunde um Karl Oettle, der im Alter von 83 Jahren gestorben ist. Wir erinnern uns an ihn als einen herausragenden Wissenschaftler, geradlinig und von hohen Graden. Beide Eigenschaften zeichneten ihn aus. War er von etwas überzeugt - von einer Sache, Person, Erkenntnis, Methode oder Aussage -, setzte er sich dafür ein: argumentativ in Wort und Schrift, stets eigenständig auch in den Begriffen und Wendungen, und unabhängig von Artefakten, Moden und Zeitgeist. Seine Studierenden, Assistenten und Kollegen kannten und schätzten und mancher Kontrahent fürchtete seine immer der Wahrheit verpflichtete Position. Selbst Nachteile für sich nahm er dann in Kauf. In mehreren Beiträgen zum 60., 70. und 80. Geburtstag (in der ZögU, Band 9, Heft 2, 1986, Band 19, Heft 1, 1996 und Band 29, Heft 1, 2006) ist über seine wegweisenden Analysen berichtet worden. Schwerpunkte seiner Werke und seines Wirkens waren Methodenfragen in der Betriebswirtschaftslehre sowie Aspekte von Management und Finanzierung in der Verkehrs-, Krankenhaus- und Kommunalwirtschaft. Obschon funktional (d.h. an Aufgaben und Aktivitäten) orientiert, kamen auch die institutionellen Restriktionen bis hin zu den volkswirtschaftlichen Rahmenbedingungen zur Sprache. Dabei spielten oft Fragen des Gemeinwohls, der Stakeholder, der Ökologie, des Raum- und Zeitbezugs eine vorrangige Rolle.

Einen Superlativ will ich an dieser Stelle wiederholen: sein unermüdlicher Fleiß. Nach seiner Emeritierung an der Universität München im Alter von 68 Jahren am 31. März 1994 erschienen bis zuletzt über 50 (!) Publikationen in Form von Aufsätzen, Thesen, Stellungnahmen und Überblicksartikeln in deutscher, einige davon auch in englischer, französischer und spanischer Sprache. Wie ein Ordinarius der alten Schule verband er Darstellung und Kritik. Kritisch ging er vor allem mit Eisen- und Straßenbahnen um, die nach seiner Auffassung weniger dem öffentlichen Interesse als dem Eigennutzen dienten.

Höhepunkte seines Gelehrtenlebens war die Verleihung des Ehrendoktors durch die Universitäten Rostock und Linz. Große Freude bereiteten ihm seine zahlreichen Schüler, wenn sie reüssierten, und seine Kollegen, soweit sie seine beherzte Gedankenfolge respektierten. Darauf kam es ihm an, nicht auf Akzeptanz.

Wir, die Mitglieder des Wissenschaftlichen Beirats des Bundesverbandes Öffentliche Dienstleistungen, vermissen Dich, verehrter lieber Kollege Karl Oettle, und wir werden Dir ein ehrendes Andenken bewahren. 